\title{
A common presentation to an uncommon disease. Penile Mondor's disease: a case report and literature review
}

This article was published in the following Dove Press journal:

International Medical Case Reports Journal

31 October 2014

Number of times this article has been viewed

\section{John CWalsh' \\ Sabré Poimboeuf ${ }^{2}$ \\ Daniel S Garvin'}

'Naval Air Station Lemoore, Lemoore, CA, USA; ${ }^{2}$ Lemoore Naval Hospital, Lemoore, CA, USA
Correspondence: John C Walsh Naval Air Station Lemoore, 937 Franklin Blvd, Bldg II, Lemoore, CA 93246, USA

$\mathrm{Tel}+\mathrm{I} 5599984330$

Fax + I 559998432 I

Email john.walsh2@med.navy.mil
Abstract: Penile Mondor's disease, or superficial thrombophlebitis of the dorsal vein of the penis, is a relatively uncommon but potentially anxiety-inducing self-limiting condition that should be easily recognizable by any primary care practitioner. It typically presents with a cord-like mass and pain to the dorsal penis and has a myriad of causes, including trauma, excessive sexual activity, excessive exercise, or malignancy. Although Penile Mondor's disease is typically a clinical diagnosis, Doppler ultrasound is the initial imaging modality of choice if there is question or doubt about the diagnosis. Accurate diagnosis and reassurance about the condition's benign and self-limiting nature assuages most patients' fears. Treatment is primarily symptomatic but may vary depending on possible underlying disease processes.

Keywords: thrombophlebitis, cord-like mass, penis, dorsal vein

\section{Case report}

A 22-year-old man with no significant past medical or surgical history, and receiving no medications, presented to his primary care provider with the chief complaint of a penile mass. The patient reported the presence of a painful cord-like mass, beginning midshaft of the penis and extending to the base of the penis and up the pubic region, that had lasted for 1 week. The mass was first appreciated while showering and cleaning the area 1 week before presentation. The patient stated that when his penis was at rest there was no pain; however, when the patient achieved an erection, attempted to have intercourse, or masturbated, particularly with any movement of his penis to the right, causing stretching of the hard "cord," he did experience discomfort. The pain was described as an achy pain with a sharp/tightness element that was present with stretching, pressure, or movement while his penis was erect. The patient denied any penile discharge, concerns for sexually transmitted infections (STIs), history of STIs, pain during urination, or testicular pain. On further questioning, the patient reported having rigorous sex 12-24hrs preceding onset of symptoms, followed by a rigorous exercise routine. The patient denied performing anal intercourse or using erectile assistive devices.

The physical exam was noteworthy for a firm, noncompressible, cord-like mass on the dorsal surface of the penis (Figure 1). The mass extended from mid-penile shaft proximally to the pubic region without any overlying erythema or associated swelling. No skin lesions were appreciated on the penis or scrotum, and no testicular masses were appreciated upon physical exam. Other than the palpable mass, no gross visible abnormalities were appreciable. 


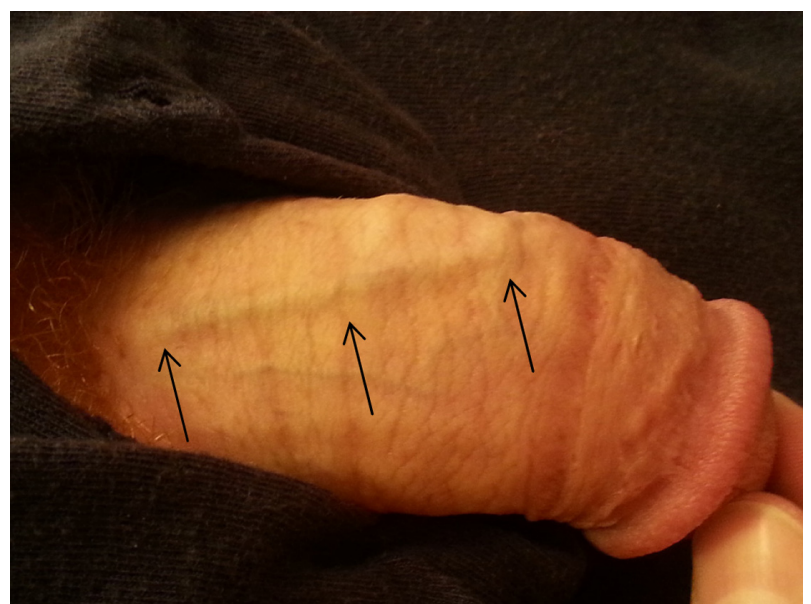

Figure I Photo of penis demonstrating slightly raised dorsal vein (arrows) without any overlaying erythema or other remarkable PE findings.

Abbreviation: PE, physical exam.

On the basis of the patient's history and physical exam, he was diagnosed with penile Mondor's disease. The patient was advised to refrain from sexual activity and was prescribed nonsteroidal anti-inflammatory drugs as needed for pain management. He was extensively counseled that he would not experience any long-term sequelae but that the mass may be present for anywhere between 3 weeks and 6 months. In addition, the patient was counseled that his sexual practices were the most likely inciting agent, and he was encouraged to refrain from such vigorous sexual activity to prevent exacerbation and/or recurrence. Last, the patient was counseled to allow his penis to "rest" and heal, including no sexual activity or masturbation until his pain resolved. Given the vast range of symptom duration documented in the literature, the patient was called 4 weeks after presenting to his primary care provider. At that time, he reported that his symptoms and mass had subsided 1-2 weeks after presentation.

\section{Discussion}

Mondor first described thrombosis of the superficial veins of the thoracoepigastric area in 1939 in female patients. ${ }^{1}$ Braun-Falco reported on superficial thrombosis of the dorsal vein of the penis in $1955,{ }^{2}$ and a case of penile thrombosis isolated to the superficial vein was reported by Helm and Hodge in $1958 .^{3}$ The reported incidence of Mondor's disease is $1.39 \% ;{ }^{4}$ however, this incidence is based on a single study of 1,296 patients. It is widely believed that the incidence is, in fact, higher and that the disease is underreported because of social fear/stigma, lack of significant morbidity, and spontaneous resolution of symptoms.

The exact pathophysiologic cause of Mondor's disease remains unknown. Numerous causes have been proposed, all of which revolve around Virchow's Triad of vessel wall damage, vascular stasis, and hypercoagulable state. The most agreed on cause is vessel wall damage resulting from prolonged vigorous sexual activity causing stretching or tearing of the vessel, usually within the preceding 24-48 hours. ${ }^{4-7}$ Vessel wall damage resulting from STIs has also been proposed; however, in a study of patients presenting to an STI clinic, it was unclear whether the presence of an STI was the causative factor or whether the patient's sexual practices and behaviors, which exposed them to the STI, was the causative factor. ${ }^{4}$ Vessel wall damage caused by injection of intravenous drugs into the superficial vein of the penis has also been reported, as well as vessel wall damage caused by exercise. ${ }^{8,9}$

Postsurgical vascular stasis has been proposed as a cause in the literature. ${ }^{5,10-12}$ Case reports of disease caused by venous stasis secondary to immobility have been described as well. ${ }^{13,14}$ One case report of venous stasis believed to be caused by a work belt causing pressure on the suprapubic region also has been reported. ${ }^{15}$ Venous stasis or hypercoagulability caused by pelvic tumors have been reported as well. ${ }^{8}$ Finally, genetic deficiencies leading to a state of hypercoagulability have been discussed in the literature, but no specific case reports have been written.

The most common methods of detection are during cleansing of the area or subsequent sexual activity (foreplay, masturbation, or sexual intercourse). ${ }^{4}$ Patients appear to present most often after 1 week of symptom duration. ${ }^{4,16}$ Penile Mondor's disease is a self-limiting disease process, and thus, treatment is limited to pain management; nonsteroidal anti-inflammatory drugs are most commonly recommended because of their pain control and anti-inflammatory effects. ${ }^{6,8,16}$ Antibiotic therapy should be initiated if there is concern for exposure to an STI, STI symptoms are concomitantly present, or concern for a superficial cellulitis exists. ${ }^{15}$ There is no evidence that anticoagulant therapy, including locally applied topical heparin, changes the outcome or duration of symptoms. ${ }^{6,8}$ In a small study of 14 patients, Mürsel Davarci presents data that a regimen of aspirin $500 \mathrm{mg}$ taken orally four times daily and pentoxifylline $600 \mathrm{mg}$ taken orally twice daily can significantly decrease duration of symptoms. ${ }^{16}$ However, that symptom resolution time is within the resolution time of documented spontaneous resolution. ${ }^{17}$ Venous resection has been discussed in the literature as a treatment method, but only in cases with persistent pain., ${ }^{5,6}$ The most commonly recommended treatment is abstinence from sexual activity until resolution of the thrombus.

The duration of symptoms reported in the literature is vast, ranging from 1 to 24 weeks. If symptoms persist or 
there is confusion about the diagnosis, ultrasound of the area is the agreed on first imaging technique and would demonstrate a noncompressible distended vein. Review of the literature demonstrates that an appropriate diagnosis can be made almost exclusively with a thorough history and focused physical exam. Nonsclerosing lymphangitis of the penis is an older term used in the literature when discussing penile Mondor's disease. ${ }^{4}$ Use of this term has prompted discussion within the literature regarding concern for differentiating between vascular and lymphatic disease via ultrasound or biopsy. Review of the literature demonstrates that this concern is overinflated and that penile thrombophlebitis, or Mondor's disease of the penis, and sclerosing lymphangitis are two distinct entities that can be differentiated by clinical history and physical exam, although Doppler ultrasound may be of benefit if there is any uncertainty. ${ }^{8}$

There is some evidence that a man who has Mondor's disease is more likely to have the disease recur, but this is believed to be a result of the continuation of predisposing actions/risk factors of the patient. ${ }^{15}$ Recurrence does not appear to change the treatment.

\section{Conclusion}

Our patient had two risk factors occur in a relatively short period of time from the onset of symptoms. Fortunately, penile Mondor's disease is a benign, self-limiting condition of the penis. It is important for primary care providers to be aware of penile Mondor's disease to be able to effectively diagnosis, manage, and counsel the patient without extensive and costly evaluation or treatment. A thorough history can most often give a clear diagnosis, as well as causative factors. If a historical cause is unclear, it is worthy of note in case the patient presents with another thrombus. An extensive workup is only warranted if there is significant concern for a hypercoagulability disorder or cancer, both of which can be evaluated with an appropriate review of systems, family history, and physical exam. Extensive or invasive treatment should be reserved only for patients whose symptoms fail to resolve with conservative therapy within 6 months or who have severe symptoms that affect their daily lives.

\section{Acknowledgment}

The views expressed in this article are those of the authors and do not necessarily reflect the official policy or position of VFA-122, Naval Hospital Lemoore, the Department of the Navy, Department of Defense, or US government.

\section{Disclosure}

The authors report no conflicts of interest in this work.

\section{References}

1. Mondor H. Tronculite sous-cutanée subaiguë de la paroi thoracigue antéro-latérale. Mem Acad Chir. 1939;65:1271-1278.

2. Braun-Falco O. Clinical manifestations, histology and pathogenesis of the cordlike superficial phlebitis forms. Dermatol Wochenschr. 1955;132(27):705-715. German.

3. Helm JD Jr, Hodge IG. Thrombophlebitis of a dorsal vein of the penis: report of a case treated by phenylbutazone (butazolidin). J Urol. 1958;79(2):306-307.

4. Kumar B, Narang T, Radotra BD, Gupta S. Mondor's disease of penis: a forgotten disease. Sex Transm Infect. 2005;81(6):480-482.

5. Sasso F, Gulino G, Basar M, Carbone A, Torricelli P, Alcini E. Penile Mondors' disease: an underestimated pathology. $\mathrm{Br}$ J Urol 1996;77(5):729-732.

6. Al-Mwalad M, Loertzer H, Wicht A, Fornara P. Subcutaneous penile vein thrombosis (Penile Mondor's Disease): pathogenesis, diagnosis, and therapy. Urology. 2006;67(3):586-588.

7. Sieunarine K. Non-venereal sclerosing lymphangitis of the penis associated with masturbation. Br J Urol. 1987;59(2):194-195.

8. Gigli F, Beltrami P, Arancio M, Zattoni F. Mondor's penile disease: personal experience. J Andrological Sci. 2008;15:152-157.

9. Öztürk H. Penile Mondor's disease. Basic Clin Androl. 2014;24(1):5.

10. Boscolo-Berto R, Raduazzo DI. Penile Mondor's disease: long-term functional follow-up. Urol J. 2012;9(2):525-526.

11. McLaren AJ, Riazuddin N, Northeast AD. Mondor meets Trendelenburg: penile vein thrombosis after varicose vein surgery. $J R$ Soc Med 2001;94(6):292-293.

12. Kutlay J, Genc V, Ensari C. Penile Mondor's disease. Hernia. 2008;12(5):557-558.

13. Conkbayir I, Yanik B, Keyik B, Hekimoğlu B. Superficial dorsal penile vein thrombosis (Mondor disease of the penis) involving the superficial external pudendal vein: color Doppler sonographic findings. J Ultrasound Med. 2010;29(8):1243-1245.

14. Day S, Bingham JS. Mondor's disease of the penis following a long-haul flight. Int J STD AIDS. 2005;16(7):510-511.

15. Griger DT, Angelo TE, Grisier DB. Penile Mondor's disease in a 22-yearold man. J Am Osteopath Assoc. 2001;101(4):235-237.

16. Mürsel Davarci EO. Penile Mondor's disease can be effectively treated with the use of an acetyl salicylic acid and pentoxifylline combination. Turk J Med Sci. 2010;40(5):735.

17. Hamilton J, Mossanen M, Strote J. Mondor's disease of the penis. West $J$ Emerg Med. 2013;14(2):180.
International Medical Case Reports Journal

\section{Publish your work in this journal}

The International Medical Case Reports Journal is an international, peer-reviewed open-access journal publishing original case reports from all medical specialties. Previously unpublished medical posters are also accepted relating to any area of clinical or preclinical science. Submissions should not normally exceed 2,000 words or

\section{Dovepress}

4 published pages including figures, diagrams and references. The manuscript management system is completely online and includes a very quick and fair peer-review system, which is all easy to use. Visit http://www.dovepress.com/testimonials.php to read real quotes from published authors. 